\title{
A Research on Tourism Market Forecast and Evaluation Based on the Application of Linear Regression Model
}

\author{
Wei Min \\ School of Management, Xiamen University \\ Xiada2000@126.com
}

\begin{abstract}
Tourism market forecast is an important tool to analyze the tourism market trends, to understand the trends of the needs of tourism market, as well as to forecast tourism demand in the direction of regional tourism development, by which the great significance for tourism product development strategy and market strategy could be carried on. The traditional prediction methods paid much more attention to the accuracy of the forecasts, ignoring the results of the feasibility of forecasting and predicting operability, which had made it difficult to predict the results of scientific testing. This paper created a scientific evaluation system for predictive value, both to ensure the accuracy, stability of the predicted value, and to ensure the feasibility of forecasting and predicting the results of operation based on simple linear regression applied to the forecasts of the tourism market. Therefore, the outcome of the tourism market forecasts in this paper can provide a scientific basis for the government to develop the policy for tourism industry.
\end{abstract}

Keywords: Linear Regression Model, Tourism Market, Forecast

\section{Introduction}

Tourism demand is not only the basis for the development of tourism industry cycle, but also the fundamental basis for the formation of the tourism market. If there is no tourism demand, tourism market to speak of, the value of tourism products will not be achieved. Tourism demand is not only the basis for the development of tourism industry cycle, but also the fundamental basis for the formation of the tourism market. If there is no tourism demand, tourism market should be out of the question, and the value of tourism products would not be achieved [1]. Therefore, the forecast of the demand for tourism products in tourism is one of the most important issues concerned about tourism management departments, tourism enterprises and tourism employees [2-3]. The importance of the tourism market demand shows that any country or region should take the demand for tourism products as the basis in the development of the tourism industry. On this basis, the tourism products can be developed purposefully, with the rational planning and control of tourism development scale and speed of development in order to achieve best value for the development of regional tourism. It is very important to research the needs of tourists, especially, the consumers' behaviors. Therefore, China's tourism industry needs this kind of research to guide the practice. The consumers' demand and behavior are changing with the social development, which needs to keep track of the industry, with the times. Tourists' demand and consumer behavior will always be the forefront of the issue of China tourism research. The scholars of China have attached great importance to this research, to continue to 
explore, as well as, to make some research results for tourism market forecast and evaluation.

With the continuous development of China's tourism industry, the social impact of tourism activities continue to increase, so the research on tourism demand began to start a deeper level, and many scholars in different fields involved in the tourism demand studies. However, in China's and other tourism market forecasts, tourism market demand forecasts focused on the phenomenon of the statistical description forecasts instead of using the model of the processes and mechanisms; empirical analysis on a consumer group or a tourist destination instead of basic theory and methodology of exploring; More emphasis on case studies, holistic approach to cases derived loosely, resulting in the problems of sample quality and representativeness, and the conclusions with no universal significance [4-5]. Therefore, this article analyzed the tourism market forecast by the point of view of the tourism market demand from based on simple linear regression model, and then try to provide a scientific basis for tourism development and planning.

\section{Literature Reviews}

Some scholars carried out on the exploration and research of tourism market forecasts from various angles. Before 1990s, a combination of research method of the qualitative and quantitative was accepted by most of scholars. After1990s, with the maturation of artificial intelligence theory and its wide application in various industries, these methods will be gradually introduced to the prediction and evaluation of tourism market research. The focus of the tourism market forecast is tourism demand forecast, but, unfortunately, domestic and foreign scholars focused on the accuracy of numerical prediction and forecasting method of choice, instead of the feasibility and operability of prediction of the forecasting results. It is shown in Figure 1:
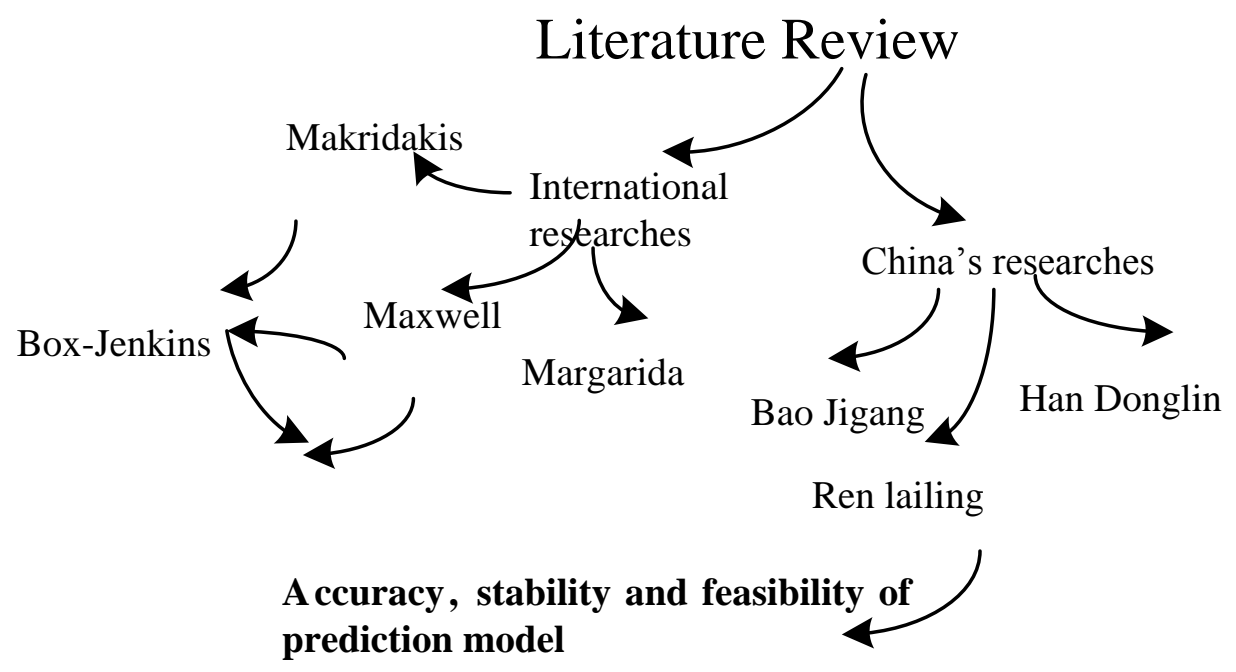

Figure 1. The Comments of Researches

Since 1980's, there are international many scholars of tourism who started the prediction of tourism market. Makridakis (1986) was to compare the different results of travel demand forecasting model, and the researchers found that the research would be 
based on their experience and the choice of different models to predict, leading to the same data to different conclusions [6-7]. N. Kulendran, Maxwell L. King (1997) applied the error correction model and time series model to forecasting the quarterly flow of international tourism, and the article prove that the error correction model results Worst based on comparing the results of tourists flow forecast quarterly flow forecasting model among the United States, Japan, Britain, Australia and New Zealand [8]. Margarida Amado, Raquel Almeida, Tilo Schwientek, Henrik Clausen (1999) forecasted the travel of Japanese tourists demand with the neural network prediction model, and the evidence showed that the results of application of neural network prediction of Japanese tourists to Hong Kong's were consistent with reality [9-10]. C.J.S.C Burger, M Dohnal, M Kathrada, R Law (2001) employed a brief description of the tourism attractions and context of Durban and South Africa to provide to give a qualitative feel of the system prior to the modeling process, by which they forecasted travel demand in Durban and South Africa with a series of time series forecasting model, and then they drew the appropriate conclusions [4]. Christine (2005) compared several exponential smoothing models to estimate and various exponential smoothing models the number of tourists from Hong Kong, Malaysia and Singapore to Australia in each quarter, and accuracy of prediction could be tested. Carey (2008) used BoxJenkins model to set up the new his own model based on structural [11] characteristics of time series, and stationary time series can be fitting according to whether smooth separable or no [12]. Therefore, Box-Jenkins model could be a theoretical basis of this article.

China's tourism market forecast late started till entering the 21 st century. More representatives of the experts and scholars in this field are Bao Jigang, Han Donglin, Zhu Liangfeng and so on. Bao Jigang (2012), applied linear regression to predict the amount of tourist visitors, taking the tourists of the Summer Palace and several other important tourist places of the park in Beijing and Guangdong as examples [13-14]. Han Donglin (2004) proposed the prediction of the inbound tourism market in current structure of China's inbound tourism and countermeasures study [15-16]. Zhuliang Feng and Pan Xin (2005), forecasted the source Nanwan scenic spot in Xinyang, China with the gray model, and the application of a gray model could explore, understand the implied internal rules from its original time data sequence in order to predict the development of trends for the tourist source market. Ren laling, Zhao Maohong and Zhao Lijun (2008) proposed an improved travel demand forecasting model and added some trend variables and dummy variables to make the model more reflect the trend of the tourism industry and the vulnerability of impact of special events based on the travel demand forecasting mode.

The research and prediction of the tourism market, tourist source for tourists in China and other countries have been made some progress, and, solved the problems of the accuracy of numerical prediction to some extent. As we all know, the tourism market projections include three elements, the accuracy of the forecast values, the feasibility of forecasting and the operation of the predicting results [17]. The prediction of the experts and scholars of China and foreign countries, however, too much emphasis on the accuracy of the forecast values neglecting the feasibility of forecasting and the operation of the predicting results. More importantly, it is very difficult to make stable value in terms of above predictive test method for testing the prediction, which is difficult to guaranteet the feasibility of forecasting and the operation of the predicting results [18-9]. Therefore, the theory and methods should be further amended above, as predicted for the tourist market, how to obtain stable, accurate predictive test value is 
very important. This paper absorbed tourists in the tourist experience in forecasting drawn by experts in the field, applied Box-Jenkins time series modeling method, selected a model with intercept term, used to correct the prediction error The serial correlation based on the application of simple linear regression model perspective, so as to provide scientific forecasts the tourism market testing methods[20]. This method ensures not only the tourism market forecast accuracy and stability, but also the feasibility of forecasting and the operation of the predicting results.

\section{Construction of the Model}

Time series analysis is an effective short-term forecasting. Stochastic process model is divided into two categories, autoregressive moving average process model and process model. The former is based on its lagged variable to calculate its future value, while the latter is the basis of past errors to calculate projected its future value. Sometimes a combination of both is required to produce autoregressive moving average model. Now, commonly used time series analysis was to establish self-regression model $(A R)$, moving average model $(M A)$, autoregressive moving average model (ARMA) and the differential autoregressive moving average model (ARIMA).

Time series model is the established model with the only of its past values and random perturbation, and the general form is as follow:

$$
X_{t}=F\left(X_{t-1}, X_{t-2}, \ldots, \mu_{t}\right)
$$

Establishing specific time series model, three problems need to be solved as follows: the specific form of the model, the lag of timing variables and the structure of random disturbance term.

General $p$-order autoregressive process $A R(p)$ is as follow:

$$
X_{t}=\varphi_{1} X_{t-1}+\varphi_{2} X_{t-2}+\ldots+\varphi_{p} X_{t-p}+\mu_{t}
$$

If the random disturbance term $\mu_{t}$ is white noise $\left(\mu_{t}=\varepsilon_{t}\right)$, then the Eq (2) is viewed as a pure $A R(p)$, being denoted:

$$
X_{t}=\varphi_{1} X_{t-1}+\varphi_{2} X_{t-2}+\ldots+\varphi_{p} X_{t-p}+\varepsilon_{t}
$$

If $\mu_{t}$ is not a white noise, it is generally considered a $q$-order moving average process $M A(q)$ :

$$
\mu_{t}=\varepsilon_{t}-\theta_{1} \varepsilon_{t-1}-\ldots-\theta_{q} \varepsilon_{t-q}
$$

Eq (4) gives a pure $M A(q)$ process. Eq (2) and (4) are combined to get a general Autoregressive moving average process $\operatorname{ARMA}(p, q)$ :

$X_{t}=\varphi_{1} X_{t-1}+\varphi_{2} X_{t-2}+\ldots+\varphi_{p} X_{t-p}+\varepsilon_{t}-\theta_{1} \varepsilon_{t-1}-\ldots-\theta_{q} \varepsilon_{t-q}$

Eq (5) shows that a random sequence of events can be generated through a process of autoregressive moving average, that is, the sequence can be explained by its own past values or lag values and random disturbance term.

If the sequence is stable, that is, its behavior does not change over time, and then the future of the sequence can be predicted through the past behavior, which is exactly the advantage of the model of random time series [21-22]. The $A R$ model is estimated by the linear equation. Therefore, $A R$ model has obvious advantages over $A R M A$ model in terms of the calculation, which can combine the accuracy of calculation and simplicity of operation with the organism. 
In this paper, the Box-Jenkins time series modeling method is applied to the construction of $A R$ model. Box-Jenkins time series model method referred to the $\mathrm{BJ}$ model, which is the most commonly useful among the time series modeling methods. In 1970, the G. E. P. Box and G. M. Jenkins of University of Wisconsin jointly published the research results of this timing analysis, which was able to use these two scholars' names, opening the curtain of modern time series study. BJ model preliminarily judged appropriate autoregressive order $p$ and moving average order $q$ of random sequence based on the statistical properties of the sample autocorrelation and partial autocorrelation function. This method can preliminarily identify $A R(p), M A(q)$ as well as low-end model $A R M A(p, q)$.

The steps of Box-Jenkins time series model construction are as follow:

For a non-stationary random time series, difference method can be applied to transforming it to be stable, and, the stable time series after difference method can be also found out the corresponding sequence of stationary random process or model. Therefore, for a nonstationary time series, the first step is to draw support d time difference to become stable, and then it can be selected in the generation model.

If the correlation coefficient of the random events sequence is of cut-off tail after $q$, while its partial autocorrelation coefficient is trailing, and this sequence is the order moving average; If the partial correlation coefficient of random events sequence is of cut-off tail after $p$, and it is trailing from the correlation coefficient; If the autocorrelation coefficients of the random events sequence began to tend to zero after $q$ order lag term, while its partial autocorrelation coefficients began to tend to zero after $p$ order lag items, this sequence is the $\operatorname{ARMA}(p, q)$ model. Table 1 shows the changes in characteristics of $A C F$ and PACF theoretical method in $A R M A(p, q)$ model.

\section{Table 1. $A C F$ and $P A C F$ Theoretical Method in $A R M A(p, q)$ Model}

\begin{tabular}{|c|c|c|}
\hline Model & $A C F$ & $P A C F$ \\
\hline$A R(p)$ & $\begin{array}{c}\text { Decay tends to } \\
\text { zero } \\
\text { (geometric or } \\
\text { oscillatory) }\end{array}$ & $\begin{array}{c}\text { cut-off tail } \\
\text { after } p\end{array}$ \\
\hline$M A(q)$ & $\begin{array}{c}\text { cut-off tail } \\
\text { after } q\end{array}$ & $\begin{array}{c}\text { Decay tends to } \\
\text { zero } \\
\text { (geometric or } \\
\text { oscillatory) }\end{array}$ \\
\hline \multirow{2}{*}{ aRMA $(p, q)$} & $\begin{array}{c}\text { Decay to zero } \\
\text { after order } q \\
\text { (geometric or } \\
\text { oscillatory) }\end{array}$ & $\begin{array}{c}\text { Decay to zero } \\
\text { after order } p \\
\text { (geometric or } \\
\text { oscillatory) }\end{array}$ \\
\hline
\end{tabular}

Seasonal changes refer to the demand for travel market which is very likely to move to one direction or to another opposite direction in a period. The seasonal trend of the market demand is usually due to a particular way, that is, the period of time the leisure needs. Although the demand for more active vacation has increased more obvious trend of price increases, it does not reduce the excessive price trends of tourism demand in each period, which will have some specific reservations about the trend still very evident. If the random sequence has trend or seasonal changes, the model identification of the data of seasonal trend should be carried out to eliminate of season and trend factors. 
After the analysis and recognition of the model category, the software of SPSS or Eviews can be applied to estimating the parameters. The core of econometric model is designed to collect information, estimate model, test model, predict with the model, solve the model, and to apply the model. EViews is an essential tool to effectively finish the tasks above. It is because of the emergence of software packages of Eviews that econometrics has been made considerable progress in the development of a practical and strict economic discipline. EViews software package can be used to analysis the data of time series and non-time series to build the statistical relationship of the sequence (variable), which can be used for forecasting, simulation, and so on.

The process of SPSS19.0 statistical analysis included several categories of descriptive statistics, mean comparison, the general linear model, correlation analysis, regression analysis, log linear models, cluster analysis, data reduction, survival analysis, time series analysis, multiple responses, and so on. Each category can be divided into several statistical procedures, such as, regression analysis can be divided into several statistical process of linear regression analysis, curve estimation, Logistic Regression, Probit regression, weighted estimates, two-stage least squares, linear regression, and so on. Besides, each process allows users to choose different methods and parameters. Based on the advantages and disadvantages of these two kinds of software, this paper will combine the EViews and SPSS.

After a conclusion from the model, the model test is necessary to test whether the parameters of the model are within reasonable limits or not, but also to test the residual sequence for models [23-24]. There are many statistical tests, including the parametric tests and non-parametric test from a large area. Parametric tests include a common test of significance F-test about the equation model and T-test of equation parameters; nonparametric tests include the sign test, rank sum test and runs test. In the SPSS statistical software, no matter which test procedures, $P$ value shown are two-tailed test results. If the one-tailed test is carried out, its procedures are just like two-tailed test, but the resulting $P$ value should be divided by 2 , and then the significant level can be compared with the expected significant. In Eviews statistical software, if the mean of a time series is constant, and the variance is constant, the difference between the values of indecent covariance measurements is only in the hands of the lag between the measured value of indecent order, and the time series can be viewed as balance.

After all the tests, the prediction should be carried out based on past data and model. Then, the model predictions are compared with the actual values to find whether the gap is limited between the acceptable range or not. When a target function is selected, each model is calculated after the election of this objective function (error function), and the model giving the minimum objective function is the best model.

Assume that the data collections are as follows:

$$
\left\{y_{i}, x_{i}\right\}_{i}=1 \rightarrow p
$$

Fitting line equation is:

$$
y=w^{\prime} \cdot x+b
$$

Then the variance can be used to measure the effect of fitting, of course, the smaller, the better. The variance is as follow:

$$
v=\sum\left(y_{i}-w^{\prime} \cdot x_{i}\right)^{2}
$$

$x_{i}, w$ are the $\mathrm{p}$-dimensional column vector, while $y, y_{i}$ are a scalar quantity.

The six steps of Box-Jenkins time series model construction can be drawn in Figure 2: 


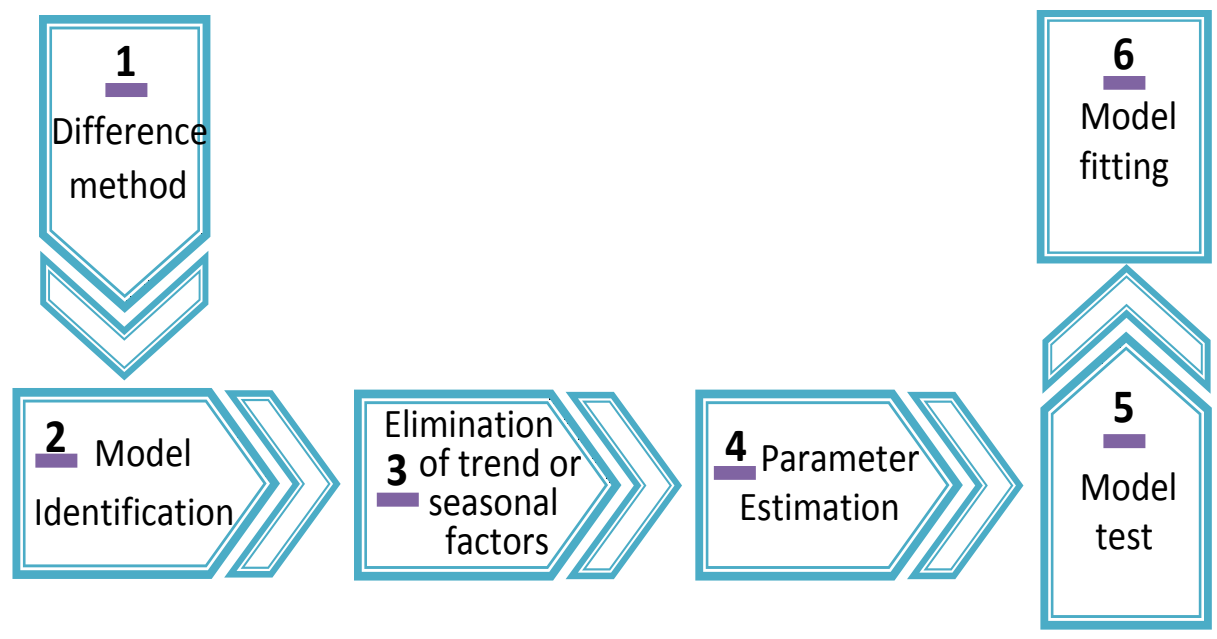

Figure 2. The Six Steps of Box-Jenkins Time Series Model Construction

\section{Forecast and Evaluation of Tourism Market in Xiamen}

Taking into account the international tourism receipts and domestic tourism revenue of various provinces in China, there is a high degree of positive correlation, whose correlation coefficient is up to 0.825 (at $1 \%$ significance level). Thus, in order to facilitate data acquisition, the tourism market forecasts can be approximately forecasted by inbound tourist market forecast in Xiamen. The total number of inbound tourists in Xiamen City from 1990 to 2009 is selected, which can be viewed as a random time series formed over time. It is denoted: $\left\{x_{t}\right\}, t=1,2, \cdots, 20$.

Table 2. The Total Number of Inbound Tourists List in Xiamen City from1990 to 2009 (Unit: million person-times)

\begin{tabular}{c|c|c|c}
\hline Year & $\begin{array}{c}\text { Person- } \\
\text { times }\end{array}$ & Year & $\begin{array}{c}\text { Person- } \\
\text { times }\end{array}$ \\
\hline 1990 & 21.08 & 2000 & 55.88 \\
1991 & 20.51 & 2001 & 57.30 \\
1992 & 25.79 & 2002 & 67.16 \\
1993 & 27.64 & 2003 & 54.88 \\
1994 & 23.04 & 2004 & 76.58 \\
1995 & 25.44 & 2005 & 94.44 \\
1996 & 33.71 & 2006 & 101.17 \\
1997 & 42.13 & 2007 & 113.29 \\
1998 & 48.39 & 2008 & 125.60 \\
1999 & 50.03 & 2009 & 136.01 \\
\hline
\end{tabular}

Source:"Yearbook of Xiamen Special Economic Zone"(1991-2010)

$\left\{x_{t}\right\}, t=1,2, \cdots, 20$ can be drawn sequence diagram, as follows: 


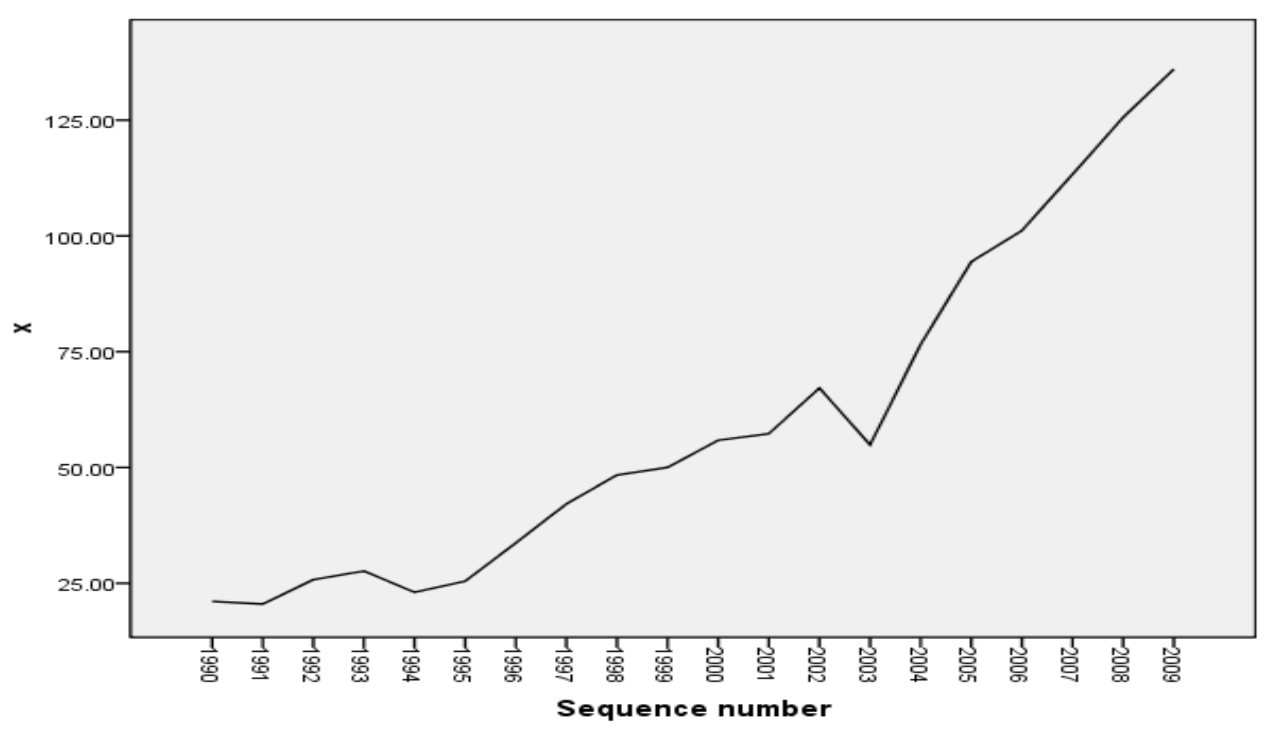

\section{Figure 3. The Total Number of Inbound Tourists List in Xiamen City from1990 to 2009 (Unit: million person-times)}

In 2003, China's sudden "SARS" （Severe Acute Respiratory Syndromes） epidemically created a sharp decline in data of inbound tourists list in Xiamen and the whole China. In order to eliminate the impact on the forecast of the fall data in 2003, the smoothing treatment of the original data in 2003 should be carried out. In actual operation, the statistical data in 2003 was instead of the arithmetic mean before and after three years, which was adjusted to 754,200 person-times.

Table 3 shows $\left\{x_{t}\right\}, t=1,2, \cdots, 20$ is a non-stationary time series, so the differential treatment can be carried out in order to obtain approximate stationary time series, as well as, $\left\{y_{t}\right\}$ can be obtained by the three times difference in of $\left\{x_{t}\right\}, t=1,2, \cdots, 20$.

Table 3. Statistical Data Results of List of Differential Data from 1990 to 2009

\begin{tabular}{l|c|c|c}
\hline Year & $\begin{array}{l}\text { The first } \\
\text { difference }\end{array}$ & $\begin{array}{l}\text { The second } \\
\text { difference }\end{array}$ & $\begin{array}{l}\text { The third } \\
\text { difference }\end{array}$ \\
\hline 1990 & N.A & N.A & N.A \\
1991 & -0.57 & N.A & N.A \\
1992 & 5.28 & 5.85 & N.A \\
1993 & 1.85 & -3.43 & -9.28 \\
1994 & -4.60 & -6.45 & -3.02 \\
1995 & 2.40 & 7.00 & 13.45 \\
1996 & 8.27 & 5.87 & -1.13 \\
1997 & 8.42 & 0.15 & -5.72 \\
1998 & 6.26 & -2.16 & -2.31 \\
1999 & 1.64 & -4.62 & -2.46 \\
2000 & 5.85 & 4.21 & 8.83 \\
2001 & 1.42 & -4.43 & -8.64 \\
2002 & 9.86 & 8.44 & 12.87 \\
2003 & 8.26 & -1.60 & -10.04 \\
2004 & 1.16 & -7.10 & -5.50 \\
2005 & 17.86 & 16.70 & 23.80 \\
2006 & 6.73 & -11.13 & -27.83 \\
2007 & 12.12 & 5.39 & -5.20 \\
2008 & 12.31 & 0.19 & -2.09 \\
2009 & 10.41 & -1.90 & \\
\hline
\end{tabular}


The scatter plot of $\left\{y_{t}\right\}$ is shown in Figure 4. Seen from Figure 4, $\left\{y_{t}\right\}$ is generally can be considered a stationary series, specifically, whether it is stable or not, it is left to continue testing.



Figure 4. Scatter Plots of Stationary Series $\left\{y_{t}\right\}$

The type of model can be analyzed and identified by examining the sample autocorrelation coefficient ( $A C F$ ) and the partial correlation coefficient ( $P A C F)$.

A self-correlation figure of stationary series $\left\{y_{t}\right\}$ can be made with SPSS, which is $A C F$ figure. See Figure 5:

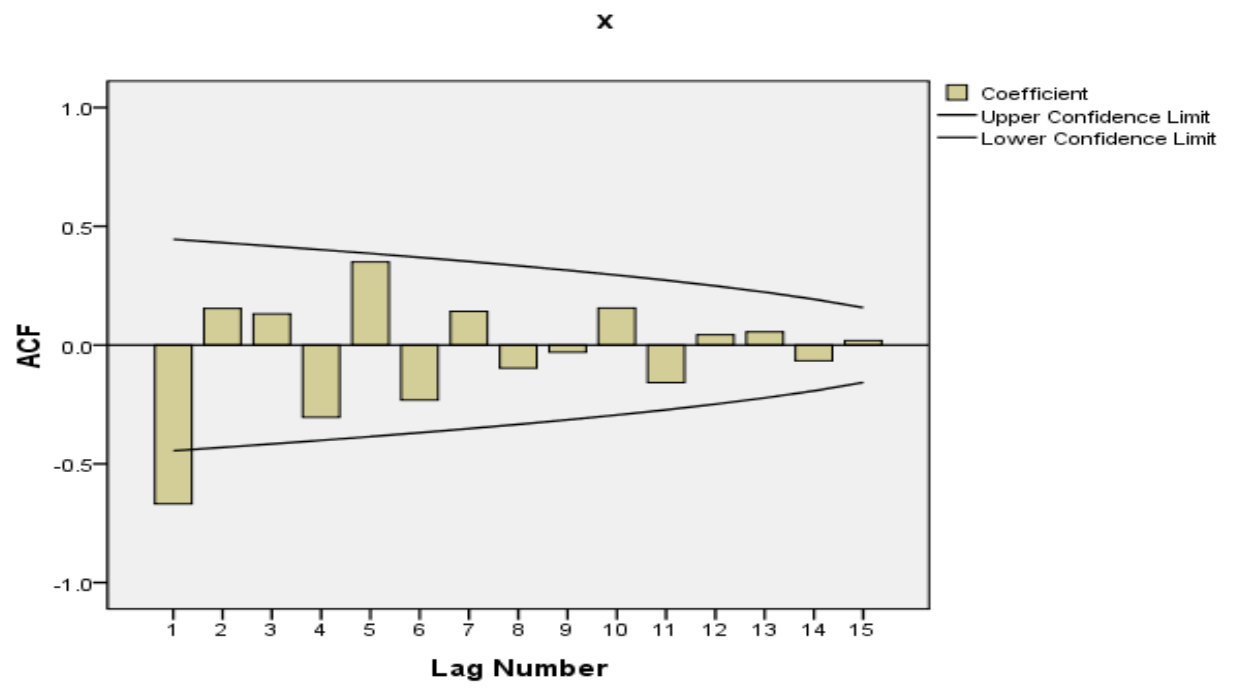

Figure 5. Autocorrelation Figure of Stationary Series $\left\{y_{t}\right\}$ 
Autocorrelation coefficient is a correlation coefficient that a time series and their sequence is in advance or lag. Autocorrelation function of the random process described is extremely useful, for which it tells us how much the sequences between adjacent data points are related to. It can be seen from the Figure 5 that the autocorrelation function was oscillating trend, and only when $l a g=1$, the confidence interval from regression break the boundaries, indicating that the sequence within the first order correlation is relatively large.

A partial autocorrelation of stationary series $\left\{y_{t}\right\}$ can be made with SPSS, which is $P A C F$ figure. See Figure 6:

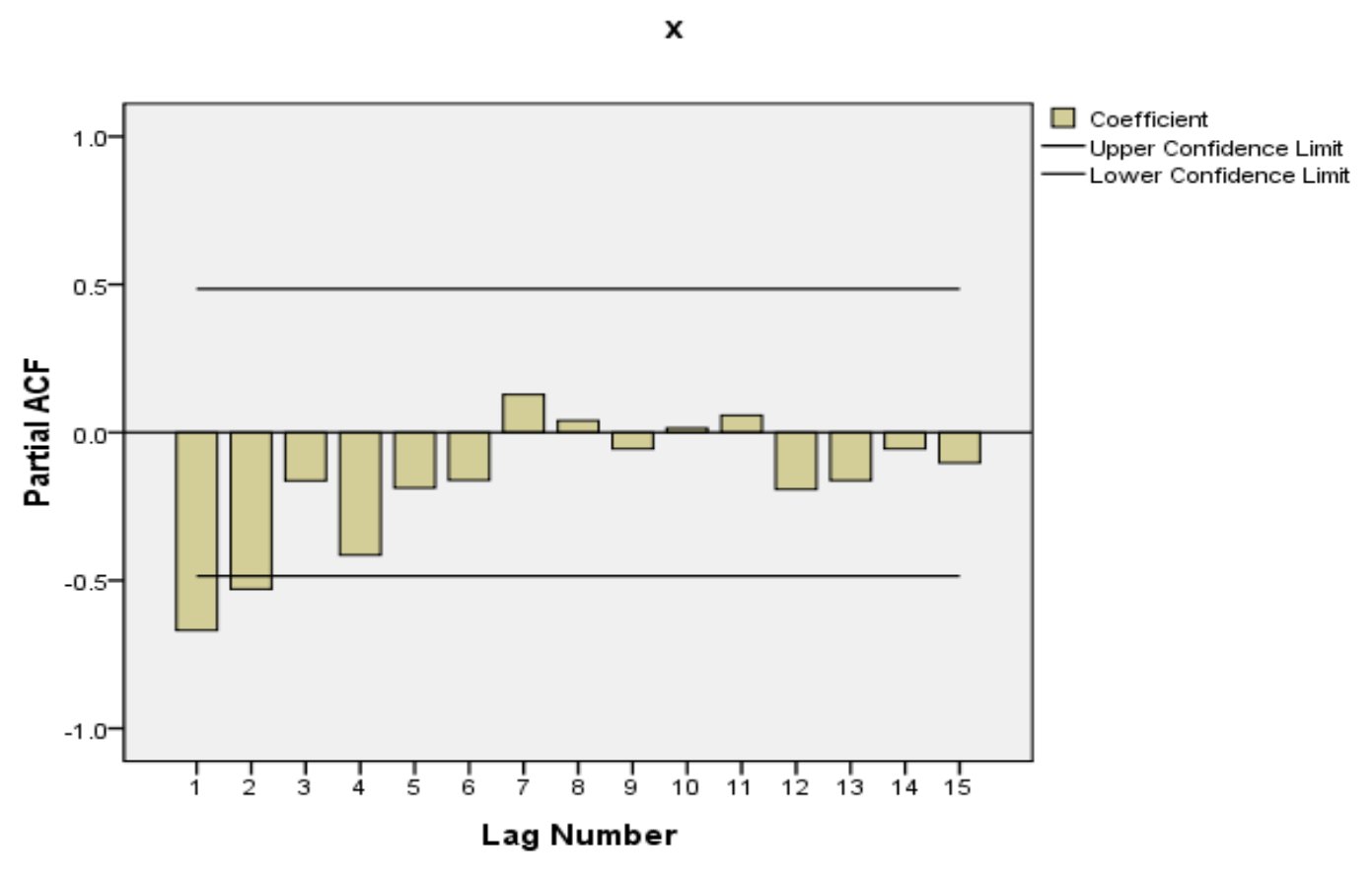

Figure 6. Partial Autocorrelation Figure of Stationary Series $\left\{y_{t}\right\}$

Autocorrelation coefficient is statistics that represents the correlation of several adjacent data, while the partial correlation coefficient is statistics to prove whether the higher order autocorrelation is important or not. Partial autocorrelation function $P A C F$ is to start from the highest order, one by one testing the partial correlation coefficients of each order whether it makes sense, until the first significant date. It can be seen from the figure 6 , when $\operatorname{lag}=1,2$, the partial autocorrelation coefficient confidence interval break the boundaries, and decreases rapidly in the future when lag $=4$.

According to these theories above, and the figures of $A C F$ and PACF for $\left\{y_{t}\right\}$, in the simple principle for the model, the time series of inbound tourist arrivals in Xiamen can be initially determined for the $A R(4)$ process, that is, fourth-order autoregressive model is concluded. Next, the parameters from the regression model $A R(4)$ should be estimated, tested and fitted.

Eviews software was applied to estimating, and the results are shown in Figure 7: 


\begin{tabular}{|c|c|c|c|c|}
\hline Variable & Coefficient & Std. Error & t-Statistic & Prob. \\
\hline C & -0.016312 & 0.310353 & -0.052559 & 0.9594 \\
\hline AR(1) & -1.412641 & 0.230703 & -6.123187 & 0.0003 \\
\hline AR(2) & -1.278060 & 0.367637 & -3.476422 & 0.0084 \\
\hline AR( 3$)$ & -0.841011 & 0.372054 & -2.260454 & 0.0537 \\
\hline $\mathrm{AR}(4)$ & -0.702642 & 0.279072 & -2.517777 & 0.0359 \\
\hline R-squared & 0.874736 & \multicolumn{2}{|c|}{ Mean dependent var } & -0.597692 \\
\hline Adjusted R-squared & 0.812104 & \multirow{2}{*}{\multicolumn{2}{|c|}{$\begin{array}{l}\text { S.D. dependent var } \\
\text { Akaike info criterion }\end{array}$}} & 13.33553 \\
\hline S.E. of regression & 5.780542 & & & 6.630595 \\
\hline Sum squared resid & 267.3173 & \multicolumn{2}{|c|}{ Schwarz criterion } & 6.847883 \\
\hline Log likelihood & -38.09887 & \multirow{2}{*}{\multicolumn{2}{|c|}{$\begin{array}{l}\text { F-statistic } \\
\text { Prob(F-statistic) }\end{array}$}} & 13.96632 \\
\hline Durbin-Watson stat & 2.122455 & & & 0.001108 \\
\hline Inverted AR Roots & $\begin{array}{l}.13+.81 \mathrm{i} \\
\text { Estimated }\end{array}$ & $\begin{array}{l}.13-.81 \mathrm{i} \\
\text { process is }\end{array}$ & $\begin{array}{l}-.84-.59 i \\
\text { nonstationa }\end{array}$ & $-.84+.59 i$ \\
\hline
\end{tabular}

\section{Figure 7. The Simulation Estimation of Stationary Series}

The expression of the corresponding model is as follow:

$$
\hat{y}_{t}=-0.016-1.413 y_{t-1}-1.278 y_{t-2}-0.841 y_{t-3}-703 y_{t-4}
$$

Shown in Figure 7, the statistics are in line with requirements, so you can assume that the above model is appropriate and reasonable, for which the model can be used in inbound tourist of Xiamen City in the short and medium term forecasts.

In addition to the above test statistics which are outside to meet the requirements in this article, we carried out the special test of residuals the corresponding model to meet the requirements. The related operation in the, Eviews software, obtain the following results can be concluded, shown in Figure 8:

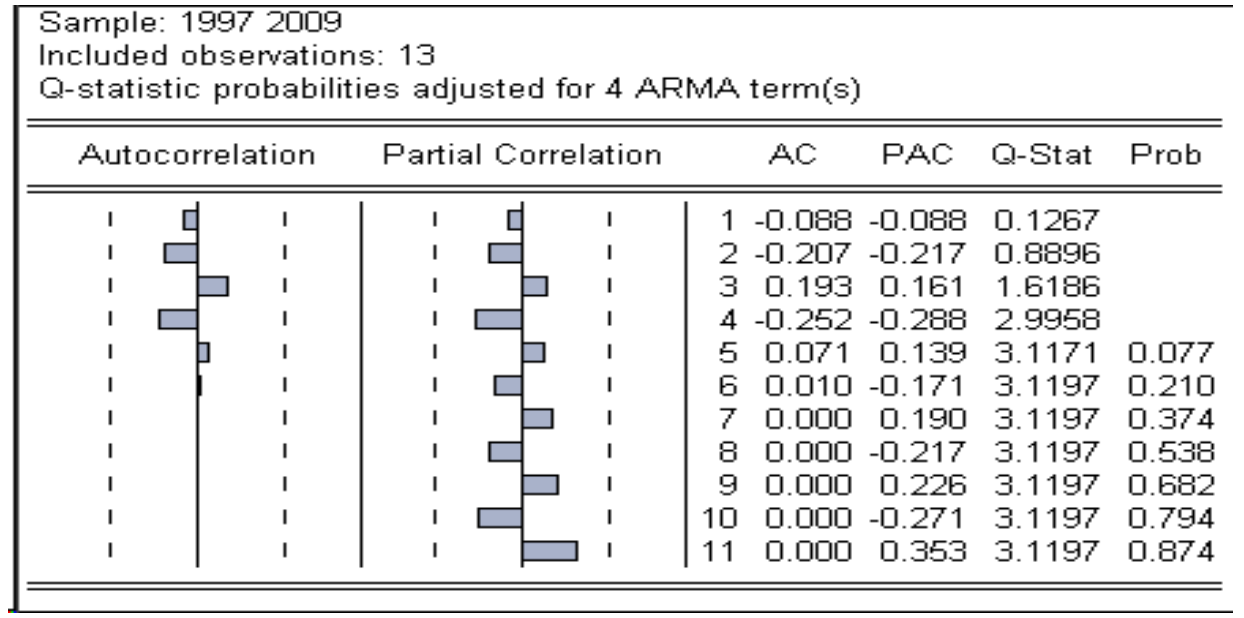

Figure 8. Model Test Chart

The left of Figure 8 shows the correlation and the partial correlation of residual series, while the right shows the relationship value of coefficient of a lag relative to each of the autocorrelation and partial autocorrelation. The column corresponding to Q-Stat is the 
corresponding degrees of freedom of the $\mathrm{Q}$ statistic value. The $\chi^{2}$ statistic value of the numbers of degrees of Prob on the right column under corresponding freedom is greater than the probability of the corresponding Q statistic. Because probability values of this column are all greater than 0.05 , indicating that the all $\mathrm{Q}$ values are less than the critical value of $\chi^{2}$

under the distribution of test level of 0.05 (critical value at the left). Therefore, conclusions should be: the random error sequence of the model is a white noise sequence, for which the model is reasonable.

For a basic understanding of the nature of the structures, but it is difficult to direct expression of mathematical models with physical type of system, another system is often applied to replacing the original system, which is known as simulation models in terms of alternative system. For example, in a model of circuit simulation, a voltage can be simulated the rate of mechanical movement; the current analog can be simulated force; capacitance can be simulated quality, and so on. Through the above-mentioned model tested, the model can be fitted, and then the model predicted values and the actual value can be observed. The fitting results are shown in Table 4:

Table 4. The Predictive Values and Actual Values of the Model

\begin{tabular}{c|c|c|c|c|c|c|c}
\hline Year & $\hat{y}_{t}$ & $\hat{x}_{t}$ & $x_{t}$ & Year & $\hat{y}_{t}$ & $\hat{x}_{t}$ & $x_{t}$ \\
\hline 1990 & N.A & N.A & 21.08 & 2000 & 12.02 & 59.07 & 55.88 \\
1991 & N.A & N.A & 20.51 & 2001 & -3.39 & 62.55 & 57.30 \\
1992 & N.A & N.A & 25.79 & 2002 & 4.60 & 58.89 & 67.16 \\
1993 & N.A & N.A & 27.64 & 2003 & -12.86 & 72.60 & 75.42 \\
1994 & N.A & N.A & 23.04 & 2004 & -1.22 & 80.86 & 76.58 \\
1995 & N.A & N.A & 25.44 & 2005 & 15.84 & 86.48 & 94.44 \\
1996 & N.A & N.A & 33.71 & 2006 & -27.22 & 101.78 & 101.17 \\
1997 & -6.54 & 41.31 & 42.13 & 2007 & 20.58 & 117.35 & 113.29 \\
1998 & 0.32 & 51.02 & 48.39 & 2008 & -3.94 & 126.86 & 125.60 \\
1999 & 2.05 & 54.54 & 50.03 & 2009 & -7.11 & 130.99 & 136.01 \\
\hline
\end{tabular}

As shown in Table 4, compared $\hat{x}_{t}$ (the predictive value of inbound tourists of Xiamen) with $\hat{x}_{t}$ (the actual value of inbound tourists of Xiamen), it was found little difference, so that the fourth order autoregressive model $A R(4)$ fitting results are satisfactory.

\section{Conclusions}

From the earlier discussion it has become very clear that the MCL cannot be used in all applications and not suitable for large system. In order to apply limiter for large capacity power system the use of high temperature superconducting fault current limiter [12-17] is one of the viable option in present days. The superconducting material exhibiting zero resistance at the superconducting state and a high resistance at the normal state is an ideal element to make fault current limiter. The movement from the superconductivity to the normal conducting state can be rapid. In this concept of protection, a superconducting device is placed in parallel with an impedance element such as a resistor or reactor. Alternatively a similar arrangement can be facilitated by means of transformer coupling. Each of these methods is discussed in turn. 
This study attempts to compensate for the theoretical prediction of the shortcomings of traditional tourism markets, because the traditional tourism market forecasts ignored the importance of the feasibility and operability for the predicted results, trying to enrich and the develop the tourism market forecast theory to some extent. The tourism market forecast is a new topic of the global scope, but also it is the key of comprehensively implement the scientific concept of development, the harmonious development of man and nature co-ordinate. Therefore, simple linear regression model proposed in this new perspective is applied to the analysis of the tourism market forecast study. Taking into account the accuracy of the forecast value, forecast the results of the feasibility and operability of prediction, it can be considered to be more effectively guide the development of the tourism market practice. The research results are not only to provide a new tourism market forecasts ideas for specific areas, but also to try to provide a theoretical basis and method selection for the country and the global tourism market forecasts by drawing general rules. At the same time, we should also see the limitations of the model, for the model is not a panacea. For example, the model does not facilitate analysis of qualitative issues, so it should be combined the qualitative and quantitative, which will continue to be in-depth study in future.

With this study, the following recommendations can be proposed for the tourism industry decision-making of government: Firstly, to change prediction model in time according to the actual situation. As tourism industry has the features of synthesis and instability, such as SARS and other emergencies, travel forecasting will also be affected by many factors. Therefore, various factors should be considered to build the model combined with qualitative analysis and the specific circumstances. It is best to use a variety of forecasting methods to improve forecast accuracy on the basis of various combinations of the model forecasts. Secondly, to rationally plan based on forecast. A more accurate prediction of the number of tourists has some significance of guidance in the practice of tourism development and planning. Therefore, a reasonable way is to determine the scale of tourism development, and to rationally allocate and improve various infrastructure and facilities based on the accurate prediction above, so that the development can be coordinated, making the tourism supply meet the tourism needs to achieve best value for economy. Thus, the out of touch of tourism supply and tourism demand can be avoided to avoid a serious shortage of supply, affecting the quality of tourist travel, as well as, to avoid the supply far more than demand, causing a huge waste of human and material resources. Finally, we cannot solely rely on prediction models. Tourism forecast is a description of the tourism industry of the future, so it is only as a basis for decision-making related industries, and the specific implementation process needs further study, instead of solely relying on prediction models.

\section{Acknowledgements}

My research project was fully sponsored by National Social Science Fund Projects of China (Research on region cluster performance on tourism industry of China) with the Grant No.14AGL015.

\section{References}

[1] L. R. Carey, "Modeling and forecasting tourism demand for arrivals with stochastic no stationary seasonality and intervention", Tourism Management, vol. 23, no. 4, (2002).

[2] R. Chambers and N. Tzavidis, "M-quantile models for small area estimation. Biometrika", vol. 93, no. 2, (2006). 
[3] C. Michael, "Time series forecasts of international travel demand for Australia", Tourism Management, vol. 23 , no. 4, (2002).

[4] C. J. S. C. Burger, M. Dohnal, M. Kathrada and R. Law, "A practitioners guide to time-series methods for tourism demand forecasting - a case study of Durban", South Africa. Tourism Management, vol. 22, no. 4, (2001).

[5] H. Donglin, "Structural Analysis and Countermeasures of China's inbound tourism", Special Zone Economy, vol. 6 , no. 11, (2004).

[6] W. Hong, Z. Li, Y. Xie and J. Wang, "A Study on the Present Situation of Tourism-Powerful Province", Theoretical Foundation and Evaluation System, Tourism Tribune, vol. 7, no. 4, (2008).

[7] H. Gao, H. Li and R. Hou, "Harmonic Response Analysis and Optimization of HZS150 Concrete Mixing Station", Journal of Theoretical and Applied Information Technology, vol. 47, no. 3, (2013).

[8] D. Li and Y. Zhao, "Rolling Sample Forecasting for Chinese International Inbound Tourism MarketBased on the ARIMA Model with Seasonal Dummy Variables”, On Economic Problems, vol. 5, no. 6, (2008).

[9] G. Li, J. Zhang and C. Huang, "A Research on the methods of causality test", Statistics and Decision, vol. 6, no. $7,(\mathbf{2 0 0 5})$.

[10] Z. Li and B. Guo, "Filtering forecasting performance of test samples from the body volume", Economic Review, vol. 7, no. 3, (2006).

[11] Z. Liang and J. Bao, "A Seasonal Study on Tourist Flows in Theme Parks during Golden Weeks_-A Case of Theme Parks in Shenzhen Overseas Chinese Town", Tourism Tribune, vol. 4, no. 1, (2012).

[12] N. Kulendran and L. Maxwell, "Forecasting international quarterly tourist flows using error-correction and time-series models", International Journal of Forecasting, vol. 13, no. 3, (1997).

[13] P. Perron, "Unit Root Tests in ARMA Models with Data Dependent Methods for the Selection of the Trunction Lag", Journal of the American Statistical Association, vol. 19, no. 10, (1995).

[14] Q. Nannan, "General Causality Test Based on Improvement of Lasso. Statistics and Information Forum”, vol. 21 , no. 2, (2008).

[15] L. Ren and Z. Liu, "A Literature Review about Tourism Demand Forecasting Methods", Tourism Tribune, vol. 3 , no. 8, (2006).

[16] L. Ren, M. Zhao and L. Zhao, “An overview of the travel demand forecast model”, Statistical Research, vol. 5 , no. 7, (2008).

[17] Y. Shen and M. Xiao, "An Empirical Test of stock market placement of shares of listed companies behavioral responses", Securities Market Herald, vol. 7, no. 3, (2001).

[18] R. S. Tsay, "Analysis of financial time series", John Wiley publications, New York (2002).

[19] W. M. Raafat and H. A. Elmotaafy, "On the Capacity of Multicell Coverage Mimo Systems in High Altitude Platform Channels", Journal of Theoretical and Applied Information Technology, vol. 47, no. 3, (2013).

[20] L. Wang and H. Liu, "Analysis of time series of the number of inbound tourism based on SARIMA model", Statistics and Consulting, vol. 5, no. 4, (2008).

[21] Y. Xie, "Discussion of tourism products and Related Issues", Journal of Northeast University of Finance, vol. 2, no. 3, (1999).

[22] L. Xiong, "The Inbound Tourism Market Statistical Analysis and Forecasting Model of Shanghai", East China Normal University, vol. 3, no. 6, (2004).

[23] L. Zhu and X. Pan, "Forecast on passenger source of tourism area based on grey model — A case study of Nanwan scenic spot in Xinyang”, Journal of Xinyang Teachers College (Natural Science Edition), vol. 18, no. 3, (2005).

[24] H. Zou, "Simulation of Linear Compressor Based on Simplorer and Maxwell", Compressor Technology, vol. 4, no. 1, (2001).

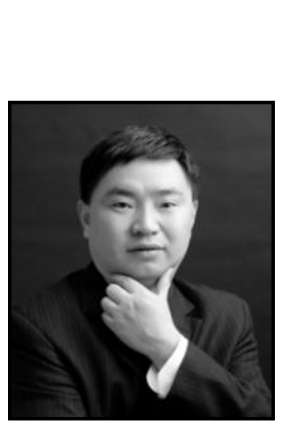

\section{Author}

Wei Min, male, Born in October, 1975, Hefei, China, Professor of School of Management, Xiamen University, Master Instructor. Research field: tourism management. 